\title{
Annual and Semiannual Variations of the Lunar Semidiurnal Geomagnetic Field Components at North American Locations
}

\author{
Wallace H. CAMPBELL \\ U.S. Geological Survey, Denver, Colorado U.S.A., \\ (Received July 7, 1978; Revised February 16, 1979)
}

\begin{abstract}
A "Fourier Analysis of Residuals" technique was used to determine the monthly average values of the semidiurnal lunar tidal component of the geomagnetic field in the quiet solar-activity year of 1965 for the three orthogonal field components, $H, D$, and $Z$. Sixteen stations that were representative of the equatorial, middle, auroral, and polar cap regions of the American sector provided the data for the determination of a latitude distribution of the lunar amplitudes and phases. The annual mean, annual variation, and semiannual variation of the geomagnetic lunar effect were separated. A series of special plots presents the results as a function of latitude in a format that gives the amount of change and month of maximum increase from the annual mean level for both the field amplitude and phase. For $H$-component amplitudes, the annal variations (about 3.5 gammas) exceed the semiannual variations near the equator and the semiannual variations are largest (about 3.0 gammas) at the auroral latitudes. The annual amplitude variations generally reach a maximum in the months just after the summer solstice. The maxima of semiannual variations occur close to the equinoxes.
\end{abstract}

\section{Introduction}

There exists a semidiurnal tidal (L2) contribution to the daily geomagnetic field change. KREIL (1850) first reported the appearance of this variation in magnetic declination measurements in Czechoslovakia. By the early part of the twentieth century, the effect was understood well enough that many of its basic global characteristics of phase and amplitude variation had been established (ChAPMAN and BARTels, 1940). In recent years comprehensive studies on the lunar tidal component have been published by Matsushita (1967), Malin (1973), and Gupta (1974). Within the Northern or Southern hemispheres, the phenomenon is often represented as the field resulting from an atmospheric current system of two opposing vortices with centers located at middle latitudes occurring about three hours before and after noon lunar time (noon corresponds 
to the upper lunar transit). This current is modified by local solar-time effects so that the principal L2 contribution to the Earth surface measured field is expected during the solar-time midday hours. An enhancement of the lunar field near the equatorial and auroral electrojet locations of the Earth is observed. Typical amplitudes of the L2 contributions are about 2 to 10 gammas (1 gam$\mathrm{ma}=10^{-9}$ Tesla). Special details of the lunar tidal component have been reported by the following authors (in addition to those above): BULLEN and CUMMACK (1953), Cain (1957), Onwumechilli and Alexander (1959), Matsushita and Maeda (1965), Bell and Defouw (1966), Malin (1967, 1971), Rastogi (1968 a, b), Malin and Leaton (1969), Chapman and Gupta (1969), Rastogi and Trivedi (1970), Chapman and Lindzen (1970), Chapman et al. (1970, 1971), Green and marlin (1971), Rao (1972), Bhargava (1972), Gupta and Malin, (1972).

The observed geomagnetic effect of lunar tides is attributable to four interrelated physical circumstances: the gravitational pull of the Moon upon the Earth's atmosphere and oceans; the dynamo-like generation of currents in the atmosphere and oceans; the daily, seasonal, and solar-activity variations of the ionosphere; and the preferential induction of currents in the conducting parts of the Earth. The gravitational pull of the Moon on the Earth as it rotates raises the atmosphere and ocean levels both on the side facing the Moon and the side away from the Moon (Wilkes, 1949; Siebert, 1961; Chapman and Malin, 1970; Malin and Chapman, 1970a). This twice-daily (semidiurnal) tidal effect occurs because the Moon's attraction overbalances the centrifugal force on the facing side of the Earth whereas the centrifugal force overbalances attraction on the away side. Viewed from above the North Pole, the Moon rotates about the Earth counterclockwise (siderial period of 27.32 days) in the same direction that the Earth orbits the Sun and spins on its axis. Thus, the Moon appears to the Earth-bound observer as rising in the east later each day by about $50.5 \mathrm{~min}$. Tides behave similarly. A lunar day, computed from $00 \mathrm{hr}$ lunar time at the lower transit of the Moon, corresponds to a duration of $24 \mathrm{hr}$ $50.47 \mathrm{~min}$ in solar time. The difference between the lunar time and the local mean solar time gives the phase angle $\nu$ (or age) of the Moon. Values of $\nu$ for the years 1850 to 2050 have been tabulated by Sugiura and Fanselau (1966).

When the conducting ocean or ionosphere is moved through the Earth's magnetic dipole field, electric currents are produced in a way similar to that of a dynamo (electric generator) in which conducting wire is mechanically forced through the field of a magnet to produce current. The current amplitudes, therefore, depend upon the velocity of transport, the Earth's field strength and direction, and the conductivity of the medium. Unlike the oceans, the ionospheric conductivity has a complex dependence upon field direction, altitude, 
composition, and electron density. The conditions within the $E$-region (about 90 to $110 \mathrm{~km}$ ) of the atmosphere are generally assumed to be most effective for the support of dynamo currents (Fejer, 1964; Matsushita, 1967; TARPley, 1970; JACKSON, 1971; EvANS, 1978). Ionization and tidal effects within this region are assemed to account for most of the day-to-night, summer-to-winter, equinoctial, and solar-cycle changes in the observed L2 field. However, MALIN et al. (1975) find reason to believe that the higher, $E$-reion levels may offer some characteristics more representative of the lunar current changes.

Only in recent years has it become apparent that tidal motions of the ocean likewise generate dynamo currents which contribute to the observed geomagnetic field changes (LARSEn and Cox, 1966; Larsen, 1968; TARPley, 1971). Malin (1969, 1970), Gupta (1974), and Shiraki (1978 a) utilized the disappearance of the ionospheric current contribution to L2 during night hours to separate out the oceanic dynamo part of the magnetic perturbation. Such method assumes only an $E$-region ionospheric source because the $F$-region contribution does not fully disappear at night. Any annual or semiannual variation of the geomagnetic lunar tidal field would not be expected to have important contributions from oceanic sources.

A varying magnetic field from current sources above the Earth's surface will induce a changing electric field and current in the conducting Earth. The depth of penetration of the field and the magnitudes of induced currents depend upon the conductivity structure of the Earth and the period of the variation. The fields from these induced currents then modify the surface observations. PrICE (1967) prepared a summary article about such induction and representative studies on this subject have been published by ECKHARDT (1963), TAKEUCHI and Saito (1963), Ashour and Chapman (1965), Banks (1969), Schubert and SCHWARTZ (1975), JADY (1975), and SHIRAKI (1978 b). The Earth's conductivity profile to at least $1,000 \mathrm{~km}$ deep can modify the induced fields that contribute to the measured semidiurnal component of the geomagnetic field.

Strong semiannual and annual variations in the general spectra of geomagnetic field amplitude changes have been reported by WARD (1960), Eckhardt et al. (1963), Banks and Bullard (1966), Currie (1966), Banks (1969), Shapiro (1969), Fraser-Smith (1972), and Campbell (1976a). The cause of the summer-winter variation has been ascribed to the enhancement of ionization in the summer ionosphere, which occurs because the electron production depends upon the cosine of the solar zenith angle (McIntosh, 1959; Fejer, 1964; Davies, 1965). The effect increases with latitude. Some small north-south ionospheric asymmetry has been attributed to the 3 percent variation in solar radiation as the Earth-Sun distance varies from perihelion (early January) to aphelion (early July). 
The cause of a semiannual variation that has its maximum geomagnetic amplitudes in the equinoctial months has been an enigma to geophysicists. The Earth reaches its maximum heliographic latitude $\left(7.2^{\circ}\right)$ on 5 March and 6 September (axial relationship) at which time 1 t may be more favorably aligned for receiving outbursts of plasma from the solar midlatitude regions (CORTLE, 1912). The equinoxes occur on 21 March and 23 September when the solar wind flow is least inclined to the Earth's geomagnetic dipole axis (BARTELS, 1932). Although questions still arise about the relative merits of the two causes for the geomagnetic effects (Priester and CAtTAni, 1962; Hundhausen et al., 1971 ), the issue seems to be resolved in favor of the "equinoctial hypothesis" (McIntosh, 1959; Roosen, 1966; Wilcox, 1968). A semiannual change in the ionization of the upper atmosphere has been recognized for a great number of years (RISHBETH and GARRIOTt, 1969). Such ionospheric effects are particularly strong at the high latitudes, where their association with an equinoctial maximum in the visual aurora occurrence is recognized (Hultevist, 1967), but the semiannual change tends to disappear at the poles where an annual variation dominates. Recently, Boller and Stolov (1970) attributed the semiannual enhancements in activity to a favorable orientation of the Earth's dipole-axis tilt at the equinoxes that allows Kelvin-Helmholtz instabilities at the boundary between the interplanetary field and the flanks of the magnetopause; such instabilities could generate a semiannual modulation of the auroral particle precipitation and geomagnetic disturbance. Russell and McPherron (1973) proposed that the semiannual variation arises from an equinoctial modulation of the southward component of the interplanetary field in its interaction with the magnetosphere.

In the present paper the annual and semiannual change in the semidiurnal lunar component of the geomagnetic variation field will be examined as a function of latitude. Clear evidence of such a seasonal variation of L2 has appeared in the scientific literature over the years (BARTels and Johnston, 1940; Bullen and Cummack, 1953; Onwumechilli and AleXander, 1959; Matsushita and Maeda, 1965; Rastogi and Trivedi, 1970; Green and Malin, 1971; Rao, 1972; Bhargava, 1972; Gupta and Malin, 1972; Shiraki, 1978 a). These presentations have been restricted to 3-month averages (seasonal presentations) of the field and/or to a limited latitude data sample. In contrast, it is the aspiration of this study to resolve the seasonal changes to an accuracy of one month or less and to investigate the latitudinal dependence of these changes from the equator to the North Pole in the American sector.

This study is a part of a program designed to investigate the predictable contributions of the quiet geomagnetic field levels for the purpose of improving the capability of geomagnetic mapping techniques. In addition, this study is a 
preparatory step in the application of geomagnetic observatory data to the determination of the Earth's conductivity characteristics. In the succeeding sections, I will present the results of the investigations as a series of amplitude and phase graphs of the three orthogonal field components in which the annual mean, annual variation, and semiannual variation contributions of L2 have been separated.

\section{Method of Analysis}

A variety of techniques has been used to resolve the semidiurnal lunar tidal component from the daily variation records of the geomagnetic field (Bartels and Johnston, 1940; Chapman and Miller, 1940; Gupta and Chapman, 1969; Malin and Chapman, 1970 b; Winch, 1970; Matsushita and CAMPBell, 1972). In their study with the "Fourier Analysis of Residuals" (FAR) technique, Matsushita and Campbell (1972) showed that a high

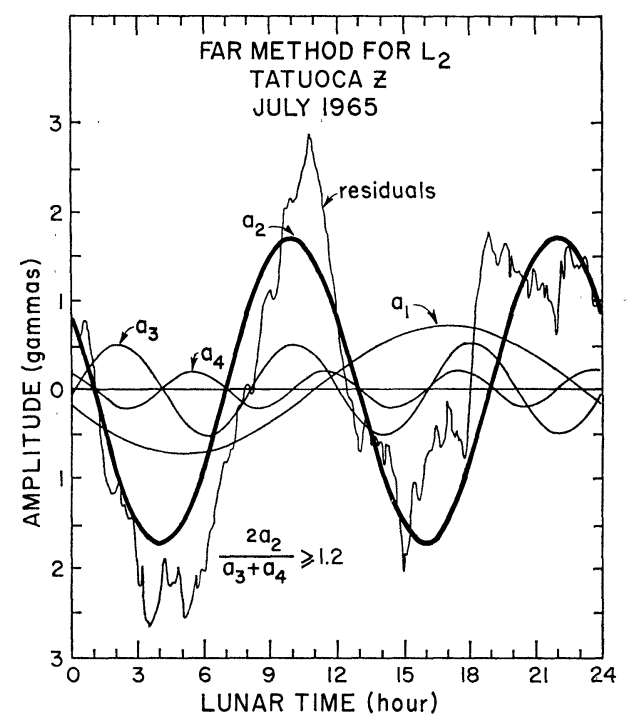

Fig. 1. Lunar time versus amplitude display of July 1965, daily residuals (see text) for the $H$ component of geomagnetic field variation at Tatuoca. The first four sinusoidal components of the the Fourier analysis of these residuals (FAR method) are shown as $\alpha_{1}$ through $\alpha_{4}$. The L2 semidiurnal lunar tidal component is indicated by the heavier line $\left(\alpha_{2}\right)$. The ratio at the bottom of the figure is the condition for acceptance of a valid level of L2. 
resolution of the month-to-month changes in L2 could be obtained within the accuracy range of the more popular Chapman-Miller method. The FAR method uses 2.5-min data samples in four principal steps: 1) the quiet-day field change, $S q$, is determined for each month; 2) the appropriate $S q$ and any linear drift in the field component level are removed from each day's data; 3) excluding full days when the planetary index of magnetic activity, $K p$, exceeds $3+$ (active days) the residuals from step number 2 are arranged in lunar time and averaged for each calendar month; 4) the best fit of the first four harmonics of a Fourier analysis of the averaged values from step number 3 is determined, and if the semidiurnal amplitude, $\alpha_{2}$, is at least 20 percent larger than the average of the third and fourth component amplitudes (i.e., if $2 \alpha_{2} /\left(\alpha_{3}+\alpha_{4}\right) \geqq 1.2$ ) then the semidiurnal Fourier component amplitude and phase is considered to be an adequate representation of the L2 variation (Fig. 1).

To determine the seasonal changes of this study the 12 monthly values of amplitude and phase for each observatory were Fourier analyzed to determine the best fit of the annual mean, annual variation, and semiannual variation for the L2 field. Figure 2 illustrates the analysis procedure for the L2 amplitudes

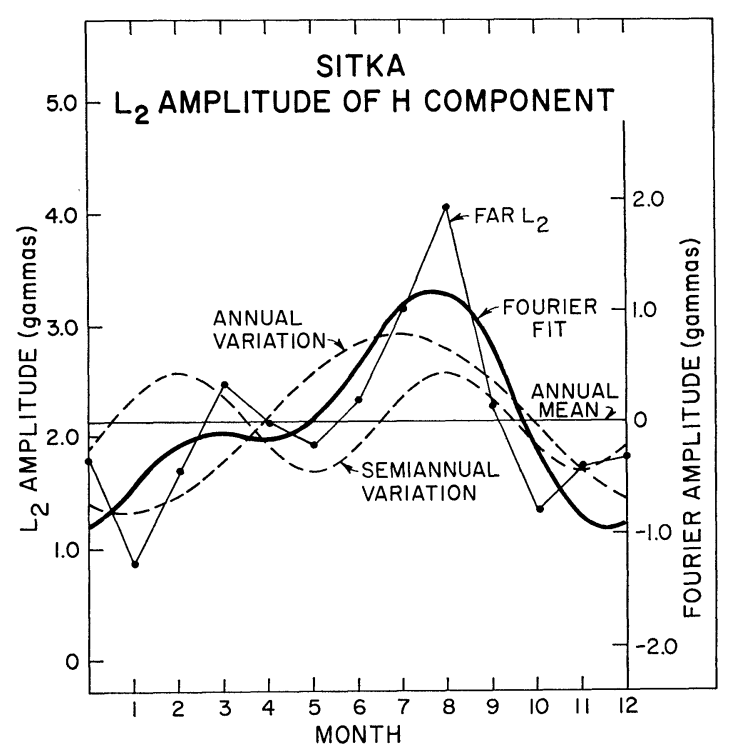

Fig. 2. Monthly values of the semidiurnal lunar tidal component L2 amplitude (FAR L2) for the $H$ direction of field at Sitka in 1965 (scale at left). The diurnal mean level, annual variation, and semiannual variation of a Fourier analysis of these monthly levels are indicated (scale at right) along with the composite of these three curves (heavy line "Fourier fit"). 
Table 1. Observatory locations.

\begin{tabular}{llrrrrr}
\hline \multirow{2}{*}{\multicolumn{1}{c}{ Station }} & \multirow{2}{*}{ Code } & \multicolumn{2}{c}{ Geographic degrees } & & \multicolumn{2}{c}{ Geomagnetic degrees } \\
\cline { 3 - 4 } \cline { 7 - 7 } & & Latitude & E. Longitude & & Latitude & E. Longitude \\
\hline HUANCAYO & HU & -12.05 & 284.67 & & -0.64 & 354.27 \\
TATUOCA & TT & -1.20 & 311.48 & & 9.51 & 21.25 \\
PARAMARIBO & PA & 5.82 & 304.78 & & 16.93 & 14.83 \\
HONOLULU & HO & 21.32 & 202.00 & & 21.17 & 266.99 \\
SAN JUAN & SJ & 18.12 & 293.85 & & 29.57 & 3.63 \\
TUCSON & TU & 32.25 & 249.17 & & 40.48 & 312.72 \\
FREDERICKSBURG & FR & 38.20 & 282.63 & & 49.54 & 350.42 \\
VICTORIA & VI & 48.52 & 236.58 & & 54.27 & 293.51 \\
SITKA & SI & 57.07 & 224.67 & & 60.09 & 275.86 \\
COLLEGE & CO & 64.87 & 212.17 & & 64.73 & 256.99 \\
BARROW & BW & 71.30 & 203.25 & & 68.64 & 241.55 \\
BAKER LAKE & BL & 64.33 & 263.97 & & 73.81 & 315.98 \\
GODHAVN & GO & 69.23 & 306.48 & & 78.78 & 33.33 \\
RESOLUTEn BAY & RB & 74.70 & 265.10 & & 83.07 & 290.20 \\
ALERT & AT & 82.50 & 297.50 & & 85.87 & 167.29 \\
THULE & TH & 77.48 & 290.83 & & 88.95 & 3.56 \\
\hline
\end{tabular}

Note: For latitude grouping purposes, the first two stations of this list are considered to be at the equatorial locations; the next six, the middle latitudes; the following four, the auroral regions; and the last four, the polar cap.

at Sitka, Alaska. When, on rare occasions, a month's value was not obtained because of the amplitude criterion (in step 4 above), an average of the adjacentmonth values was substituted.

The original data source consisted of computer tapes of 2.5-min digitized samples of the three orthogonal geomagnetic field components through the quiet sun year of 1965 from 16 observatories in the Western Hemisphere. These records were supplied by World Data Center A in Boulder, Colorado. Table 1 is a list of station locations and illustrates their even distribution in the four geomagnetic latitude zones; equatorial, middle, auroral, and polar-cap.

The seasonal variations of the phase or amplitude of $\mathrm{L} 2$ at a station were represented in the form $f(\mathrm{~L} 2)=a_{n} \cos (n \theta)+b_{n} \sin (n \theta)$ where $n=1$ for the annual term, $n=2$ for the semiannual term, and $\theta$ is the angular representation of the month. These $a$ and $b$ coefficients for each of the 16 stations were then plotted with respect to the geomagnetic latitude and a smooth curve was drawn through the points. An example of the $a_{2}$ and $b_{2}$ semiannual coefficients of L2 amplitudes is shown in Fig. 3. I occasionally used personal weighting judgment in drawing the smooth curves through the data; e.g., note the $b_{2}$ value for $\mathrm{RB}$ in this figure. The standard deviation of the variances between the data points and smooth curve is discussed later. Two-degree latitude values of $a_{n}$ and $b_{n}$ 


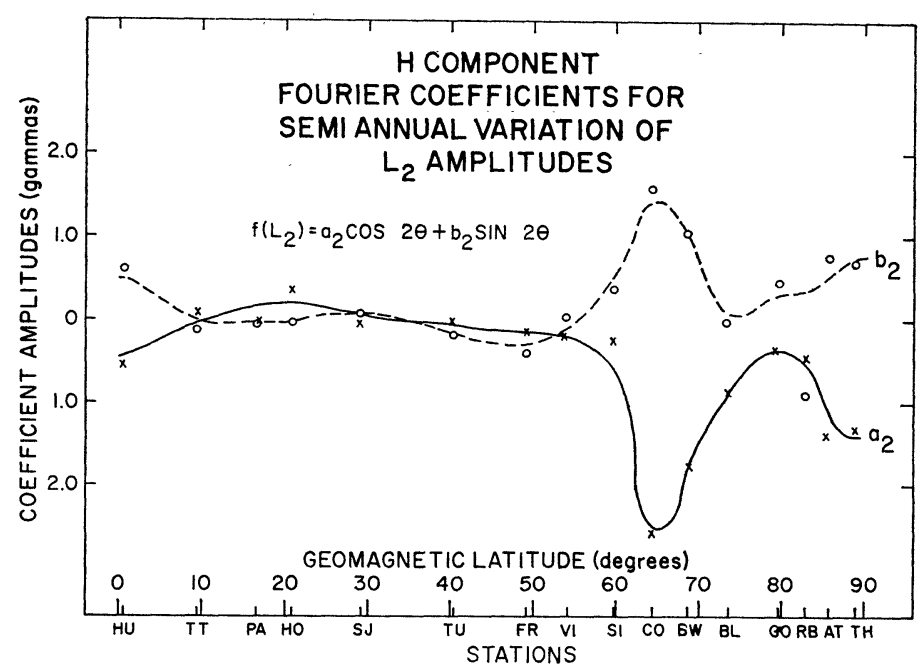

Fig. 3. Geomagnetic latitude display of the Fourier coefficients of the semiannual variation terms $a_{2}(x)$ and $b_{2}(o)$ obtained from the analysis of the monthly changes in $H$ component amplitudes of the lunar component, L2, and represented in the form $f(\mathrm{~L} 2)=a_{2} \cos 2 \theta+b_{2} \sin 2 \theta$ (where $\theta$ is the angular representation of the months). Stations supplying data for the analyses are indicated with code letters (Table 1) along the latitude axis. The continuous and dashed curves are a smoothed, hand-drawn fit to the $a_{2}$ and $b_{2}$ values.

were next read from the smooth curve and the annual and semiannual amplitude and phase changes for each latitude were reconstructed from the following relationships:

$$
\text { Amplitude }=\left(a_{n}{ }^{2}+b_{n}{ }^{2}\right)^{1 / 2} ; \quad \text { Phase }=\tan ^{-1}\left(b_{n} / a_{n}\right) .
$$

The four options for displaying a latitude arrangement of station data are to use geographic, dip, geomagnetic, or invariant latitude coordinates. Several trial plottings of the data revealed that not one of these arrangements offered the best advantages at all latitudes. The first two options seemed good at low latitudes; the latter two were better at high latitudes. I have elected to use a geomagnetic latitude display (Table 1) with an equatorial region modification. To allow the geographically south location behavior of Huancayo and Tatuoca to be meshed with the remaining geographically north data, the annual mean phase values of $D$ and $Z$ were reversed to reflect the Northern Hemisphere expectations (Matsushita, personal communication).

The $\mathrm{L} 2$ computations give the field amplitude in gammas $\left(10^{-9} \mathrm{Tesla}\right)$ and the hour of first maximum (phase) of the semidiurnal change. In this paper 
the annual and semiannual variation in the amplitude of L2 with latitude will be represented in terms of the amplitude of the change from the annual mean level (in gammas); also, the month of maximum increase from this mean will be given. The annual and semiannual variation in phase of L2 with latitude will be represented by the amplitude of the change from the annual mean level of phase (in hours); the month of maximum increase in phase from the mean will be given.

Two methods were used to evaluate the accuracy of the measurements of L2 seasonal changes. First, I determined the standard deviations, $\sigma$, for the variance of the computed monthly values from the three-term Fourier analysis fit. Average values, $\bar{\sigma}$, for representative latitude groups are illustrated in Table 2. Generally, the larger $\bar{\sigma}$ were associated with the larger amplitude values of L2. The values given in Table 2 were found to represent the dominant errors for the annual mean levels of lunar amplitude and phase. Second, the standard deviation of the variance of the station's $a_{n}$ and $b_{n}$ values from the smoothed latitude curve were computed. For each latitude group the average of these standard deviations was determined and converted to the equivalent amplitude and phase representation. These values are listed below each of the relevant displays.

To assist the reader in interpreting the subsequent figures representing the L2 variability with season, I have included a line-thickness code of three levels. The thinnest lines indicate amplitudes below 0.2 gammas and the thickest lines indicate amplitudes above 0.5 gammas. For example, a thin line showing a major phase excursion of one field component should not be considered as a serious contributor to the field change at that observation latitude.

Table 2. Fit* of Fourier analysis to 12 monthly L2 values.

\begin{tabular}{lllllll}
\hline \multirow{2}{*}{ Latitude } & \multicolumn{2}{c}{ Amplitude (gammas) } & & \multicolumn{2}{c}{ Phase (hours) } \\
\cline { 2 - 7 } & $H$ & $D$ & $Z$ & & $H$ & $D$ \\
\hline Equatorial $\bar{\sigma}$ & 1.0 & 0.3 & 0.4 & 0.5 & 1.1 & 0.5 \\
Middle $\bar{\sigma}$ & 0.2 & 0.6 & 0.2 & 1.0 & 0.5 & 0.8 \\
Auroral $\bar{\sigma}$ & 0.7 & 0.5 & 0.5 & 1.0 & 1.2 & 1.6 \\
Polar cap $\bar{\sigma}$ & 0.7 & 0.5 & 0.7 & 1.6 & 1.0 & 1.1 \\
\hline
\end{tabular}

* Standard deviations, $\sigma$, for the variance of monthly L2 values from the sum of the first three Fourier components. $\bar{\sigma}$ is the average $\sigma$ for the given latitude group.

\section{Results}

\subsection{Annual mean (Figs. 4, 5, and 6)}

The latitudinal representation of the annual mean $\mathrm{L} 2$ amplitude and phase 
indicates the levels from which the seasonal variations are computed. In the region of the equator the $H$ field component is most important; the amplitudes there reach about 5.5 gammas. Typical of an effect apparently related to the east-west alignment of the electrojet current in that region, the $D$ component is much smaller than $H$ and remains at a level near 1.5 to 2 gammas through the entire low latitudes. The $Z$ component is equivalent to $D$ in amplitude near the equator but decreases with latitude until the auroral region is reached. In the middle latitudes, where the principal lunar tidal source-current foci are located, the $D$ components exceed $H$ as expected. At high latitudes the lunar $H$ amplitude levels are larger than $D$ and, thus, indicate an alignment effect from the westward-flowing auroral electrojet current. The large $Z$ component in this region could result from the location variability of that jet current. Peak values of L2 occur at about $8 \mathrm{hr}$ lunar time near the equator, occur at

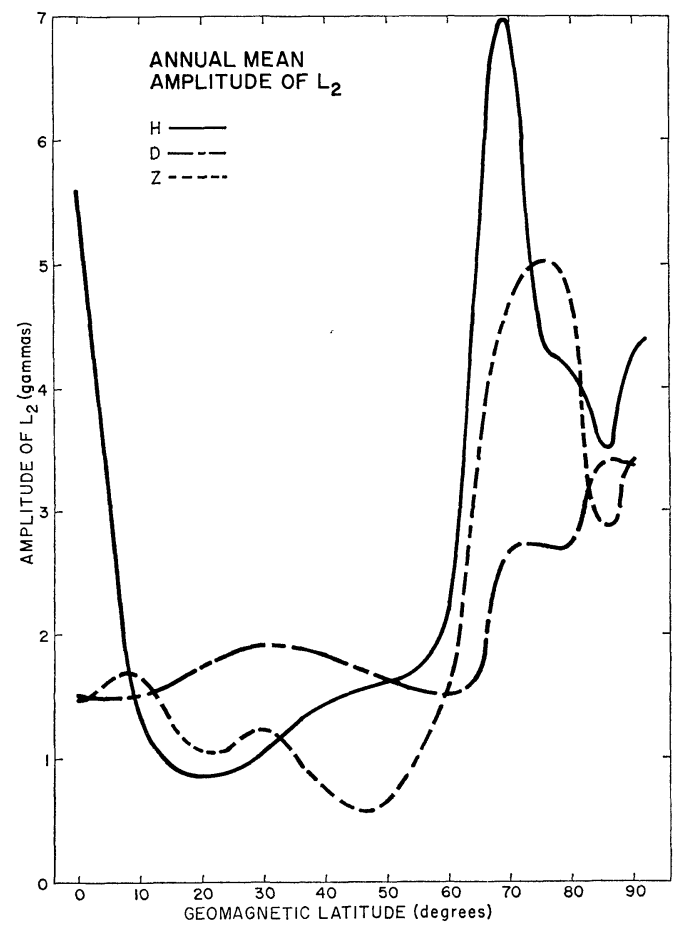

Fig. 4. Geomagnetic latitude representation of the annual mean amplitudes of the semidiurnal lunar tidal component (L2) of field variation is given for the three orthogonal directions $H, D$, and $Z$. At the bottom of the figure the corresponding average standard deviations, $\bar{\sigma}$, for the four representative latitude zones are shown (see text for details). 
about $7 \mathrm{hr}$ lunar time in the middle and high latitudes, and shift toward the lunar midnight near the pole.

The annual mean $H$ and $D$ horizontal amplitude components of the lunar tidal field may be combined with their computed phases to produce a diagram of the horizontal field vectors in latitude versuslu nar-hour coordinates. Matsushita (personal communication) provided such a synthesis of Figs. 4 and 5 from which an equivalent source current can be inferred (at $90^{\circ}$ lag and at an amplitude proportional to the field vectors). The resulting field vector diagram, Fig. 6 , seems to indicate the existance of two large-area, poorly defined, current foci in the region of $30^{\circ}$ to $40^{\circ}$ latitude near 3- and 9-hr lunar time; and, also, two small-area, well defined, current foci close to $80^{\circ}$ latitude at about 2.5 - to 9-hr lunar time. These patterns repeat 12 hours later in the second half-day. The latitude location of the midlatitude foci is higher than that reported by MAtsushita and MAEDA (1965) but similar to the location reported by CHAPMAN and Bartels (1940) and Malin (1973). Such differences may be due to the selection of sampling years and to a foci shift with solar cycle (MALIN et al.,

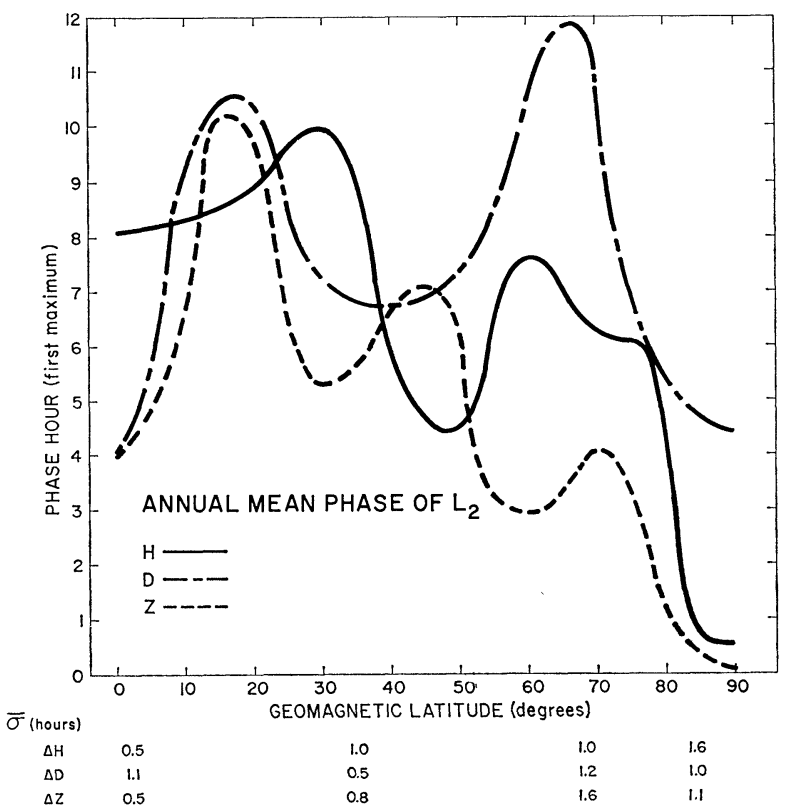

Fig. 5. Geomagnetic latitude representation of the annual mean phase hour of first maximum in the semidiurnal lunal tidal component (L2) of field variation is given for the three orthogonal directions $H, D$, and $Z$. At the bottom of the figure, the corresponding average standard deviations, $\bar{\sigma}$, for the four representative latitude zones are shown (see text for details). 


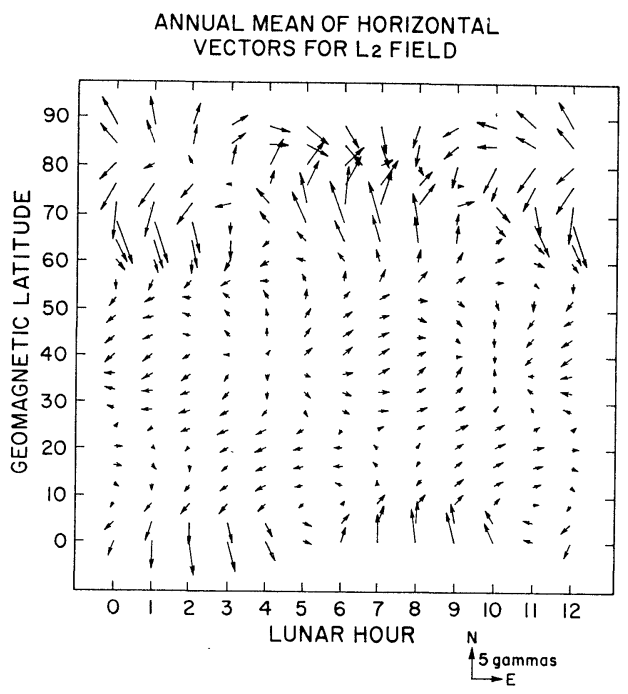

Fig. 6. A synthesis of the $H$ and $D$ field amplitude and phase of Figs. 4 and 5 to show the annual mean horizontal field vector changes in lunar hour and geomagnetic latitude for the first half-day. This pattern is repeated from 12 to 24 hours lunar time.

1975.) The two high-latitude foci were not anticipated in the results published by the above authors. This omission may be due to the scarcity, in those reports, of observatory records from the auroral zone and polar cap.

\subsection{Annual variations (Figs. 7, 8, 9, and 10)}

Figure 7 shows an annual variation of L2 amplitudes that has low values from about $10^{\circ}$ to $55^{\circ}$ latitude. The extremely large $H$ amplitude at the equator is almost two-thirds that of the annual mean at that location. The relatively low $D$ values for this annual variation indicate an alignment of the L 2 current determined by the electrojet. The $H$ in these regions is at maximum in January and February (Fig. 8). One would expect the L2 variation to be largest in the summer months. The abnormal low latitude behavior illustrated in Fig. 8 has been noted by other authors (CHAPMAN and RAJA RAO, 1965; GuPTA, 1974; and ShIraki, $1978 \mathrm{a}, \mathrm{b}$ ).

In middle latitudes both $D$ and $H$ are small, although larger than $Z$ at most locations. A seasonal motion of the $\mathrm{L} 2$ current vortices could account for the spread of months in which the maximum $H$ annual variation appears in these regions.

In the auroral latitudes, near $65^{\circ}$, the $H$ amplitudes are again the largest 


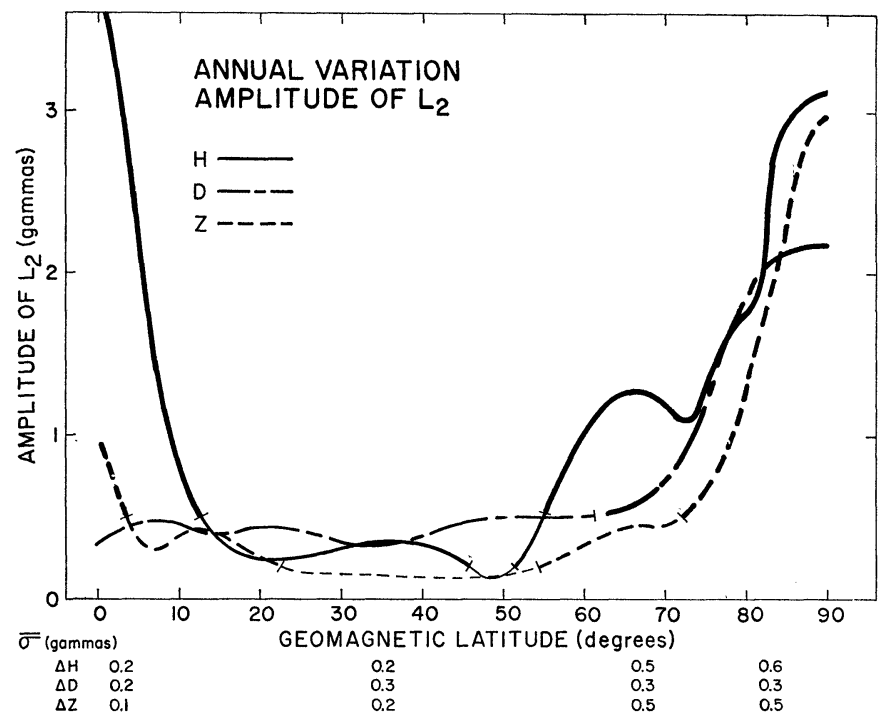

Fig. 7. Geomagnetic latitude representation of the annual variation amplitude of the semidiurnal lunar tidal component (L2) of field variation is given for the three orthogonal directions $H, D$, and $Z$. At the bottom of the figure the corresponding average standard deviations, $\bar{\sigma}$, for the four representative latitude zones are shown (see text for details). The three increasing line widths indicate amplitude levels of $<0.2$ gammas, 0.2 to 0.5 gammas, and $>0.5$ gammas respectively.

of the three field components, as might be expected from an influence of the electrojet current. At the polar cap, where the solstitial variation in solar zenith angle is most striking and an annual change in location of the polar lunar-current foci (Fig. 6) may be expected, all field components show a sharp rise in annual variation amplitudes. In these latitudes the months of maximum increase in amplitude are found just after the time of smallest midday solar zenith angle, during the post-summer-solstice period, when there also would be a maximum atmospheric heating.

Figures 9 and 10 illustrate how the phase of the semidiurnal lunar component shifts from the annual mean as a result of the summer-winter variation, Of particular significance are the 1-hr increase in the time of the $H$ component maximum in June near the equator, the $2.5-\mathrm{hr}$ increase in June the $H$ component in the auroral regions (and corresponding decreases for this component in both these areas in December), and the large variation of $Z$ phase between the auroral region and polar caps. 


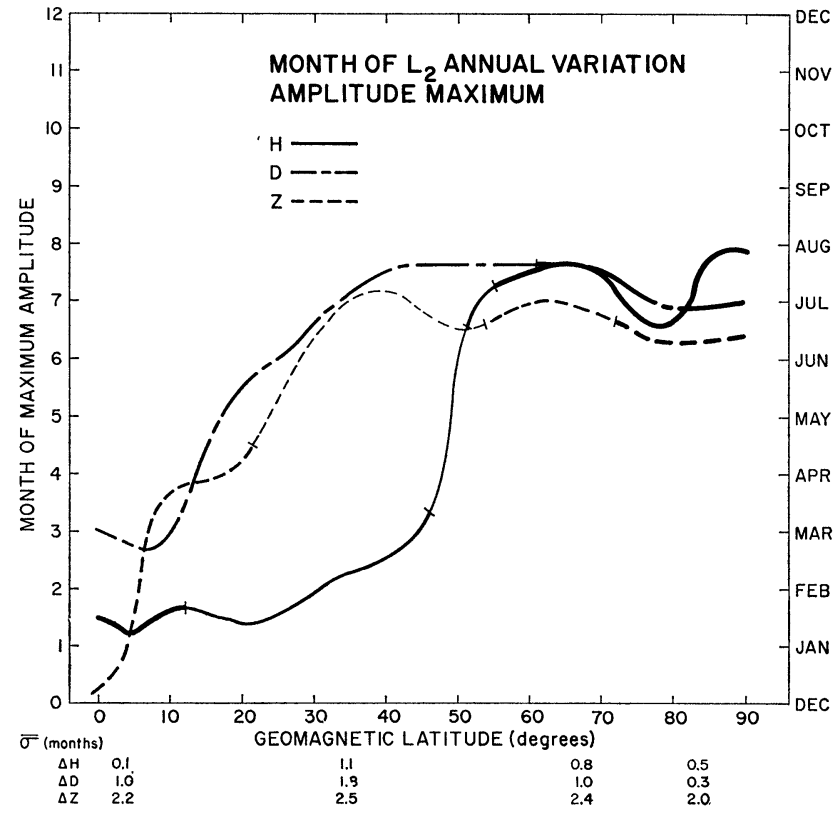

Fig. 8

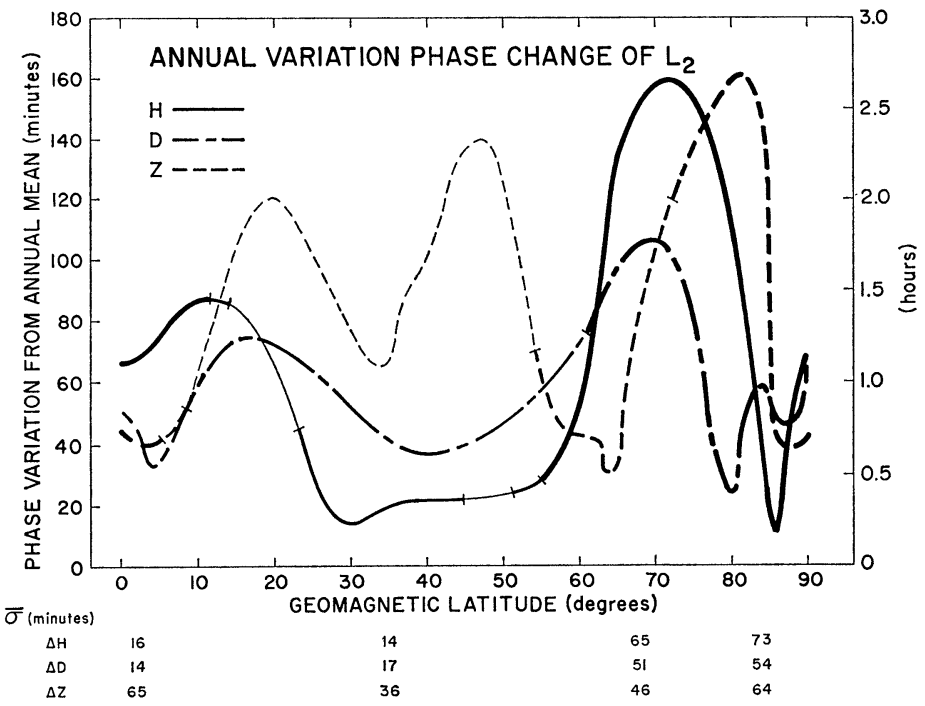

Fig. 9 


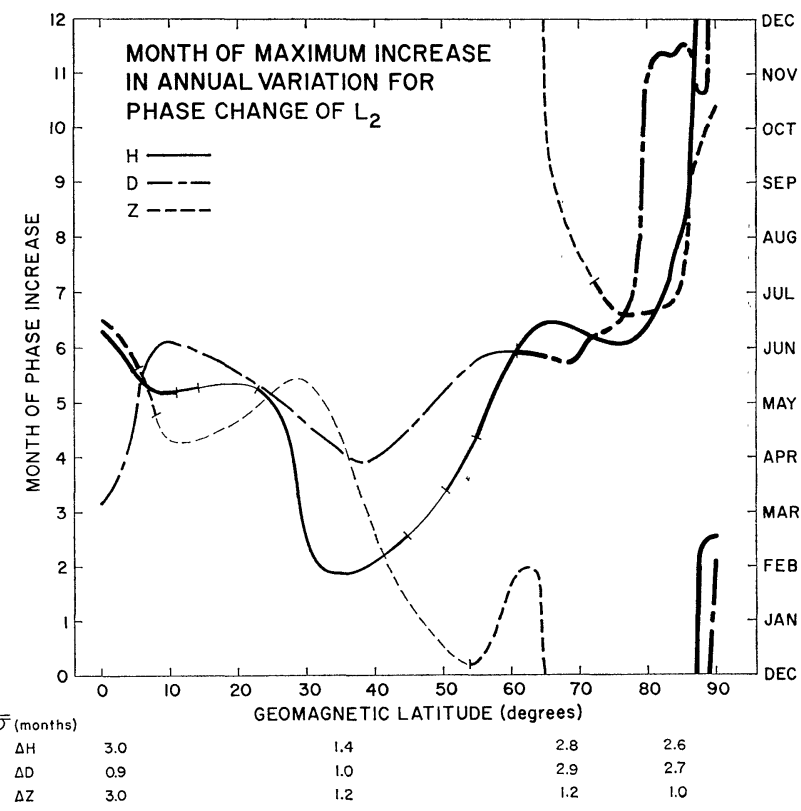

Fig. 10

Fig. 8. Geomagnetic latitude representation of the month of annual variation amplitude maximum (the scale gives midmonth positions) of the semidiurnal lunar tidal component (L2) of field variation is given for the three orthogonal directions $H, D$, and $Z$. At the bottom of the figure the corresponding average standard deviations, $\bar{\sigma}$, for the four representative latitude zones are shown (see text for details). The three increasing line widths indicate amplitude levels given in Fig. 7.

Fig. 9. Geomagnetic latitude representation of the annual variation of phase change (in min or hr) from annual mean level for the semidiurnal lunar tidal component (L2) of field variation is given for the three orthogonal directions $H, D$, and $Z$. At the bottom of the figure the corresponding average standard deviations, $\bar{\sigma}$, for the four representative latitude zones are shown (see text for details). The three increasing line widths indicate amplitude levels given in Fig. 7.

Fig. 10. Geomagnetic latitude representation of the month of maximum increase on the annual variation for the phase change of the semidiurnal lunar tidal component (L2) of field variation is given for the three orthogonal directions $H, D$, and $Z$. The scale gives midmonth posi tions At the bottom of the figure the corresponding average standard deviations, $\bar{\sigma}$, for the four representative latitude zones are shown (see text for details). The increasing line widths indicate amplitude levels given in Fig. 7. 
3.3 Semiannual variations (Figs. 11, 12, 13, and 14)

Although there is some semiannual enhancement of $D$ and $H$ lunar amplitudes at equatorial latitudes, the striking feature is that the semiannual change

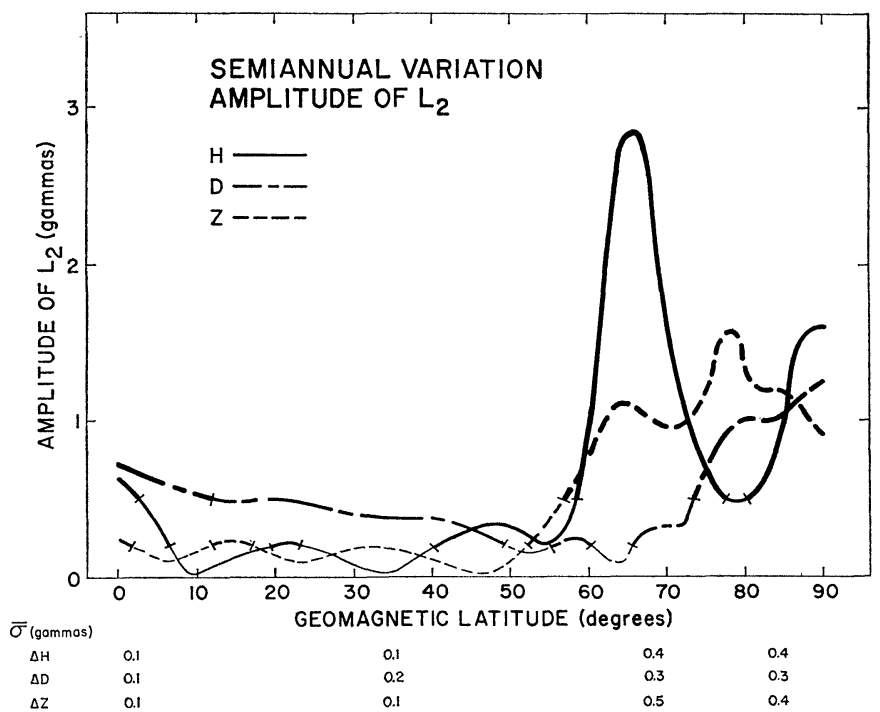

Fig. 11

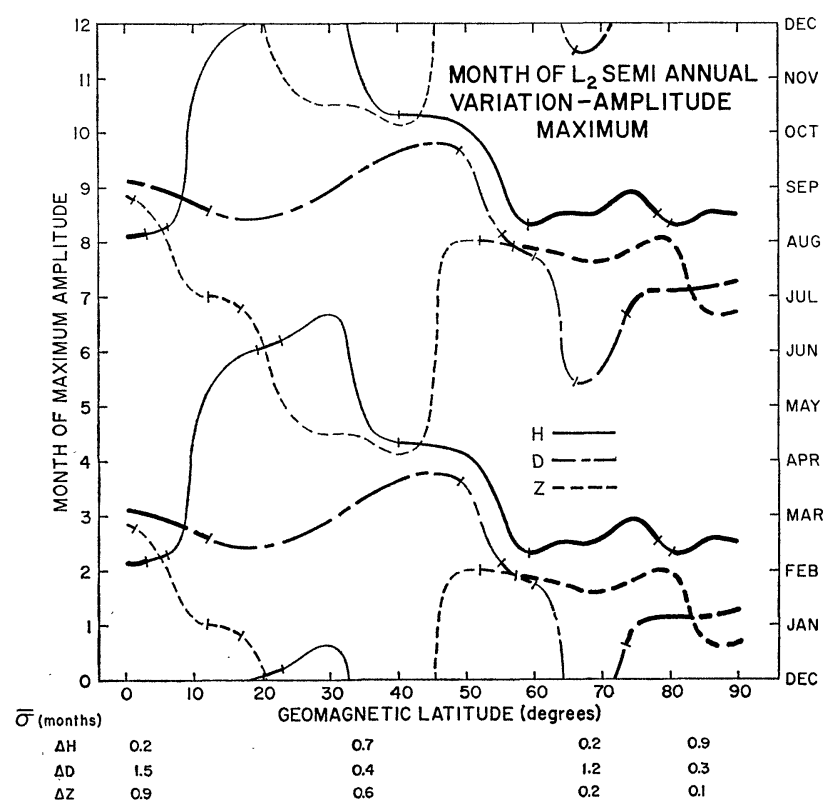

Fig. 12 


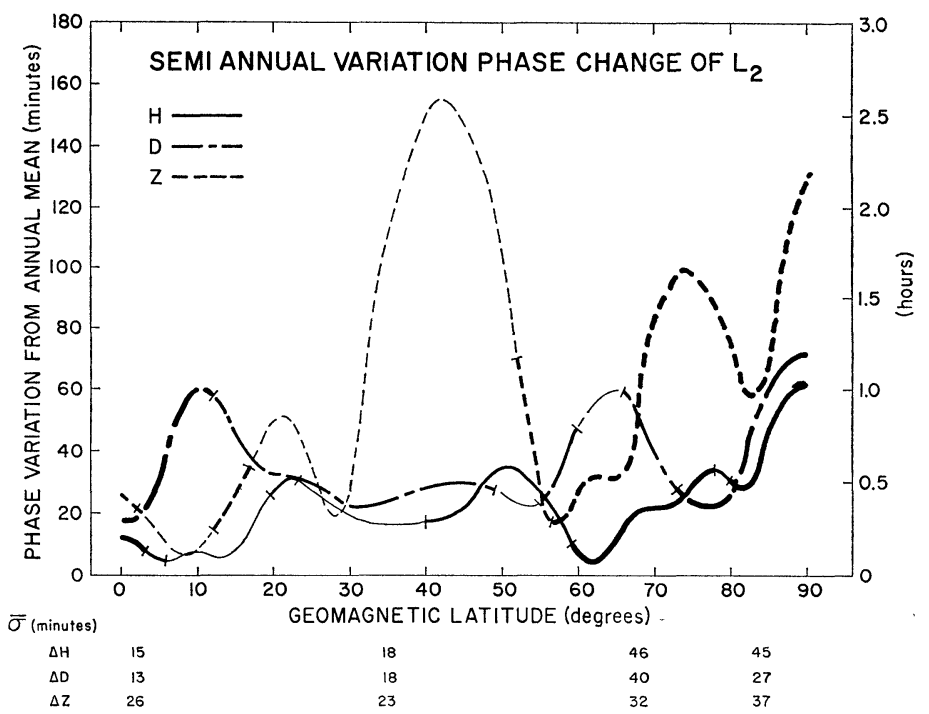

Fig. 13

Fig. 11. Geomagnetic latitude representation of the semiannual variation in amplitude of the semidiurnal lunar tidal component (L2) of field variation is given for the three orthogonal directions $H, D$, and $Z$. At the bottom of the figure the corresponding average standard deviations, $\bar{\sigma}$, for the four representative latitude zones are shown (see text for details). The three increasing line widths indicate amplitude levels of $<0.2$ gammas, 0.2 to 0.5 gammas, and $>0.5$ gammas, respectively.

Fig. 12. Geomagnetic latitude representation of the months of semiannual variation amplitude maxima (the scale gives midmonth positions) of the semidiurnal lunar tidal component (L2) of field variation is given for the three orthogonal directions $H, D$, and $Z$. At the bottom of the figure, the corresponding average standard deviations, $\vec{\sigma}$, for the four representative latitude zones are shown (see text for details). The three increasing line widths indicate amplitude levels given in Fig. 11.

Fig. 13. Geomagnetic latitude representation of the semiannual variation phase change (in min or hr) from the annual mean level for the semidiurnal lunar tidal component (L2) of field variation is given for the three orthogonal directions $H, D$, and $Z$. At the bottom of the figure the corresponding average standard deviations, $\bar{\sigma}$, for the four representative latitude zones are shown (see text for details). The three increasing line widths indicate amplitude levels given in Fig. 11. 
in $H$ is only about one-sixth the annual change (Fig. 11). The semiannual change in ionospheric total electron content is indeed large for these regions (Yonezawa, 1965). However, studies by Tarpley and Balsley (1972) on the electric field in the equatorial $E$-regions principally show the existence of an annual variation in its semidiurnal lunar component.

At auroral latitudes the uniquely large semiannual $H$ component (about 3 gammas) is about twice the annual change. The important semiannual maximum in auroral particle precipitation, which is responsible for a local ionization enhancement, is well established. In describing the seasonal variation of the aurora with increasing latitude toward the pole, Hultevist (1967) states, "...the summer minimum becomes progressively deeper with increasing latitude, whereas the winter minimum becomes progressively shallower, disappears, and is replaced by a maximum, which is then the only one in the distribution." The annual and semiannual variations in the lunar component geomagnetic field amplitudes (c.f. Figs. 7 and 11) follow a somewhat similar pattern.

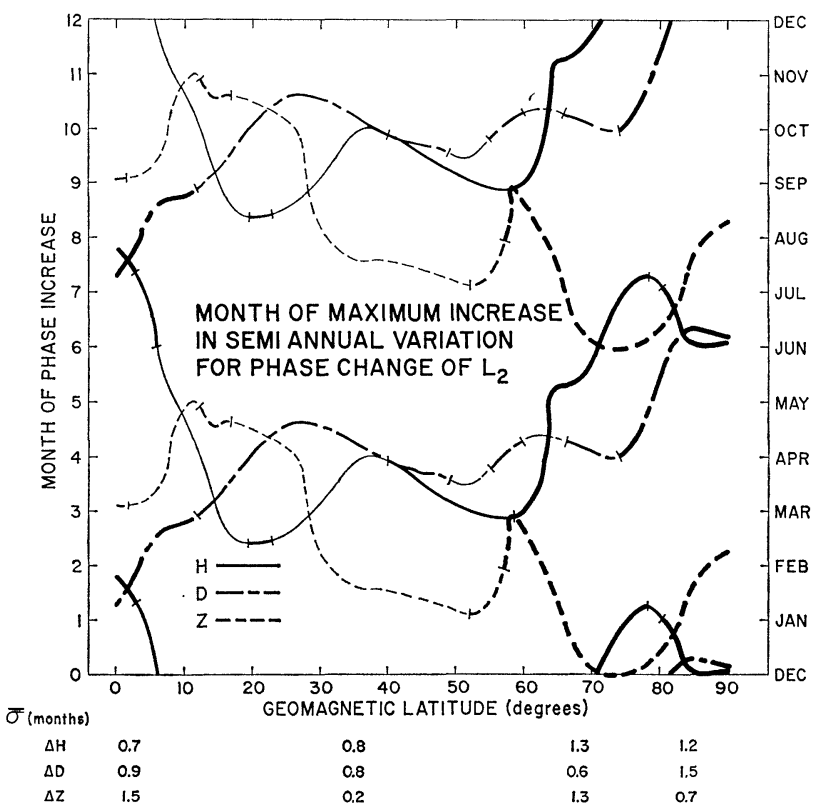

Fig. 14. Geomagnetic latitude representation of the months of maximum increase in the semiannual variation for the phase change of the semidiurnal lunar tidal component (L2) of field variation is given for the three orthogonal directions $H, D$, and $Z$. The scale gives midmonth positions. At the bottom of the figure the corresponding average standard deviations, $\bar{\sigma}$, for the four representative latitude zones are shown (see text for details). The three increasing line widths indicate amplitude levels given in Fig. 11. 
The semiannual $H$ and $D$ maximum amplitudes occur near the equinoctial months at the equator (Fig. 12). The $H$ amplitudes at the auroral zone and polar cap clearly favor those months also. However, the high-latitude $D$ and $Z$ maxima occur in earlier months. It is interesting that the semiannual phase shift for L2 is typically under $1 \mathrm{hr}$ for $H$ (Fig. 13) even in the auroral zone in contrast to the larger shifts of phase associated with the annual change. Instances of large $D$ amplitudes of the semiannual variation do show extreme 1 to 2-hr shifts in phase. Because the phase shifts for $H$ are small, the months of their maximum contribution to the annual means are not significant. The June and December phase increases of about $1 \mathrm{hr}$ in the polar cap lunar $H$ occur when then the respective amplitudes are about 1.5 and 1.0 gammas (Fig. 14).

\section{Summary}

The three data groups (annual mean, annual variation, and semiannual variation) of the L2 field contribute in different ways to the amplitudes determined in the four latitude regions. Near the equator, $H$ component levels are particularly large (equatorial electrojet current effect) in the annual mean (about 5.5 gammas) and annual variation levels (about 3.5 gammas), whereas the semiannual levels show only a minor enhancement (summer-winter ionization effect dominates). In the middle latitudes the annual and semiannual variations are about one-tenth the annual mean (about 1 to 2 gammas), and the $D$ component is often larger than $H$ (current vortex region effect). At auroral latitudes, $H$ dominates all three components (auroral electrojet current effect); the important semiannual variation (auroral ionization effect) is about four-tenths of the annual mean level (about 7 gammas) and twice the annual variation. Within the polar cap the annual variation values of the L2 field reach about the size of the 3- to 4-gamma annual mean (large seasonal ionization effect).

The hour of maximum for the annual mean level of L2 is about $8 \mathrm{hr}$ (and $20 \mathrm{hr}$ ) lunar time for $H$ near the electrojet current regions of the equator and high latitudes. For the other latitudes and other field components, this time of maximum changes greatly, seeming to satisfy the source-current flow patterns. The annual variation part of the $H$ component adds a phase change of about $1 \mathrm{hr}$ near the equator, under $0.5 \mathrm{hr}$ in midlatitudes, about $2.5 \mathrm{hr}$ at the auroral zones, and about $1 \mathrm{hr}$ in the polar cap. The semiannual variation part of the $H$ component is under $0.5 \mathrm{hr}$ at all latitudes except the polar cap (where it is 0.5 to $1.0 \mathrm{hr}$ ).

The L2 annual variation in amplitude is at maximum typically between January and February for the equatorial to middle latitudes and between July and August at higher latitudes. This variation seems to be anomalously 6 
months out of place for the northern hemisphere low latitude stations. The maxima of semiannual variation in amplitudes occur close to the equinoctial months of March and September in the equatorial and auroral regions where the amplitudes are significantly large. At the polar-cap locations the maxima shift 1 to 2 months earlier, as if the annual changes were exerting some controlling influence.

This study of L2 is a part of a detailed investigation of the spectral composition of the geomagnetic fields in North America. One purpose of the investigation is to determine the predictable characteristics of field levels on undisturbed days in order to evaluate the limitations of accuracy obtainable in magnetic mapping, to improve the selection of favorable times for survey observations, to adjust various field measurements to more reproducible baselines, and to find the modifications of the measurements by the induced fields. The studies started at the short period end of the spectra at $0.3 \mathrm{sec}$ (WERTZ and CAMPBell, 1976) and have already extended to field variations with periods of $4 \mathrm{hr}$ (CAmpbell, $1976 \mathrm{a}, \mathrm{b}, 1977 \mathrm{a}, \mathrm{b})$. Before investigating the solar-quiet $(S q)$ diurnal and semidiurnal variations (24- and $12-\mathrm{hr}$ periods) it was necessary to extract the lunar contributions to the semidiurnal field changes. The present paper fulfills that purpose; L2 values from this analysis are now being removed from $S q$ as that evaluation proceeds. The figure presentation format was specifically designed to permit an interested reader to determine more easilly the limits of the lunar tidal effects on the geomagnetic field contribution to be expected on quiet days in North America.

I wish to thank Bernice Bender for her assistance in the computer programming for the FAR analysis. Dr. S. Matsushita kindly provided the computations for Fig. 6 and numerous worthwhile discussions on lunar effects in geomagnetism. The original data were graciously supplied by World Data Center A through the kind actions of Alan Shapley, J. Virginia Lincoln, and William Paulishak.

\section{REFERENCES}

Ashour, A.A. and S. Chapman, The magnetic field of electric currents in an unbounded plane sheet, uniform except for a circular area of different uniform conductivity, Geophys. J., 10, 31-44, 1965.

BANKs, R.J., Geomagnetic variations and the electrical conductivity of the upper mantle, Geophys. J. R. Astr. Soc., 17, 457-487, 1969.

BANKs, R.J. and E.C. Bullard, The annual and 27 day magnetic variations, Earth Planet. Sci. Lett., 1, 118-120, 1966.

Bartels, J., Terrestrial-magnetic activity and its relations to solar phenomena, Terr. Mag. Atmos. Elect., 37, 1-52, 1932.

Bartels, J. and H.F. Johnston, Geomagnetic tides in horizontal intensity at Huancayo, Parts I and II, Terr. Mag. Atmos. Elect., 45, 269-308, 485-512, 1940. 
Bell, B. and R.J. Defouw, On the lunar modulation of geomagnetic activity, 1884-1931 and 1932-1959, J. Geophys. Res., 71, 4599-4603, 1966.

Bhargava, B.N., Semiannual and annual modulation of the magnetic field, Planet. Space Sci., 20, 423-427, 1972.

Boller, B.R. and H.L. Stolov, Kelvin-Helmholz instability and the semiannual variation of geomagnetic activity, J. Geophys. Res., 75, 6073-6084, 1970.

Bullen, J.M. and C.H. Cummack, The lunar diurnal variation of the Earth's magnetic field for all elements, Amberly, New Zealand, J. Geophys. Res., 58, 554-556, 1953.

CAIn, J.C., An analysis of the solar and luni-solar daily variations in the geomagnetic field at Sitka, Alaska, 1902-1952, Rept. Geophys. Inst., U. of Alaska, AFCRF/TR 57-273, 1957.

CAMpbell, W.H., An analysis of the spectra of geomagnetic variations having periods from 5 min to 4 hours, J. Geophys. Res., 81, 1369-1390, 1976 a.

CAmpbell, W.H., Spatial distribution of geomagnetic spectral composition for disturbed days, J. Geomag. Geoelectr., 28, 481-496, 1976 b.

CAMPBell, W.H., Spectral characteristics of field variations during geomagnetically quiet conditions, J. Geomag. Geoelectr., 29, 29-50, 1977 a.

CAmpbell, W.H., Spectral characteristics of geomagnetic field variations at low and equatorial latitudes, J. Atmos. Terr. Phys., 39, 1217-1227, 1977 b.

Chapman, S. and J. Bartels, The lunar daily magnetic variation, Chapter VIII, in Geomagnetism, pp. 244-271, Clarendon Press, Oxford, 1940.

Chapman, S. and J.C. Gupta, Notes on the computation of solar and lunar daily magnetic variations of $X$ and $Y$ from hourly and bihourly values of $H$ and declination, Gerlands Beitr. Geophysik, 78, 103-114, 1969.

Chapman, S. and R.S. Lindzen, Atmospheric Tides, 200 pp., D. Reidel Pub. Co., Cordrecht, 1970.

Chapman, S. and S.R.C. Malin, Atmospheric tides, thermal and gravitational: nomenclature, notation and new results, J. Atmos. Sci., 27, 707-710, 1970.

Chapman, S. and J.C.P. Miller, The statistical determination of lunar daily variations in geomagnetic and meteorological elements, Monthly Not. Roy. Astr. Soc., Geophys. Suppl., 4, 649-669, 1940.

Chapman, S. and K.S. Raja Rao, The $H$ and $Z$ variations along and near the equatorial electrojet in India, Africa and the Pacific, J. Atmos. Terr. Phys., 27, 559-581, 1965.

Chapman, S., J.C. Gupta, and S.R.C. Malin, Note (2) on the computation of solar and lunar geomagnetic variations, Gerlands Beitr. Geophysik, 79, 5-10, 1970.

Chapman, S., J.C. Gupta, and S.R.C. Malin, The sunspot cycle influence on the solar and lunar daily geomagnetic variations, Proc. Roy. Soc. London, 324, 1-15, 1971.

Cortie, A.L., Sunspots and terrestrial magnetic phenomena 1898-1911: The cause of the annual variation in magnetic disturbances, Monthly Not. Roy. Astr. Soc., 73, 52-60, 1912.

Currie, R.G., The geomagnetic spectrum-40 days to 5.5 years, J. Geophys. Res., 71, 4579-4598, 1966.

Davies, K., Ionospheric Radio Propagation, 470 pp., N.B.S. Monograph 80, U.S. Dept. Commerce, 1965.

ECKHARDT, D.H., Geomagnetic induction in a concentrically stratified earth, J. Geophys. Res., 68, 6273-6278, 1963.

ECKHARDT, D.H., K. LARNER, and T. MAdDin, Long-period magnetic fluctuations and mantle electrical conductivity estimates, J. Geophys. Res., 68, 6279-6286, 1963.

Evans, J.V., A note on lunar tides in the ionosphere, J. Geophys. Res., 83, 1647-1652, 1978.

FEJER, J.A., Atmospheric tides and associated magnetic effects, Rev. Geophys., 2, 275-309, 1964. 
Fraser-Smith, A.C., The spectrum of geomagnetic activity index Ap, J. Geophys. Res., 77, 4209-4220, 1972.

Green, P. and S.R.C. MALIN, Lunar and solar daily variations of the geomagnetic field at Watheroo, Western Australia, J. Atmos. Terr. Phys., 33, 305-318, 1971.

Gupta, J.C., Lunar ionospheric and oceanic dynamo variations, Gerlands Beitr. Geophysik, 53, $1-15,1974$.

Gupta, J.C. and S. Chapman, Lunar daily harmonic geomagnetic variation as indicated by spectral analysis, J. Atmos. Terr. Phys., 31, 233-252, 1969.

GuPTA, J.C. and S.R.C. MALIN, Seasonal variations in the solar and lunar daily geomagnetic variations, Geophys. J. R. Astr. Soc., 30, 11-18, 1972.

Hultqvist, B., Aurora, Chapter IV-2, in Physics of Geomagnetic Phenomena, edited by S. Matsushita and W.H. Campbell, pp. 663-791, Academic Press, New York, 1967.

Hundhausen, A.J., S.J. BAme, and M.D. Montgomery, Variations of solar-wind plasma properties: Vela observations of a possible heliographic latitude dependence, J. Geophys. Res., 76, 5145-5154, 1971.

J ACKsON, J.S., Diurnal variation of the geomagnetic field 2. The lunar variation, J. Geophys. Res., 76, 6909-6914, 1971.

$J_{A D Y}$, R.J., Upper-mantle conductivity determined by the geomagnetic lunar daily variation, Phys. Earth Planet. Inter., 10, 377-381, 1975.

KreIL, K., Einfluss des Mondes auf die magnetische Deklinatin, Denkschr. Akad. Wiss. Wein Math. Naturw. Kl., 3, 1-47, 1850 (reported in Chapman and Bartels, 1940, p. 244).

LARSEN, J.C., Electric and magnetic fields induced by deep!sea tides, Geophys. J. R. Astr. Soc., 16, 47-70, 1968.

LARSEN, J. and C. Cox, Lunar and solar variations in the magnetotelluric field under the ocean, J. Geophys. Res., 71, 4441-4445, 1966.

MALIN, S.R.C., Luni-solar daily veriations of the geomagnetic field at observatories in the British Isles during the IGY, Geophys. J. R. Astr. Soc., 13, 397-401, 1967.

MALIN, S.R.C., The effect of the sea on lunar variations of the vertical component of the geomagnetic field, Planet. Space Sci., 17, 487-490, 1969.

MALIN, S.R.C., Separation of lunar daily geomagnetic variations into parts of ionospheric and oceanic origin, Geophys. J. R. Astr. Soc., 21, 445-455, 1970.

MALIN, S.R.C., Morphology of the lunar daily geomagnetic variation and its relation to $S$, Gerlands Beitr. Geophysik, 80, 151-153, 1971.

MALIN, S.R.C., Worldwide distribution of geomagnetic tides, Philos. Trans. Roy. Soc. London, Ser. A, 274, 551-594, 1973.

MALIN, S.R.C. and S. Chapman, Lunar tidal components N1 and $\mathrm{O} 2$ in the atmospheric pressure, Pure Appl. Geophys., 80, 309-318, 1970 a.

MALIN, S.R.C. and S. ChAPMAN, The determination of lunar daily geophysical variations by the Chapman-Miller method, Geophys. J. R. Astr. Soc., 19, 15-35, 1970 b.

MAlin, S.R.C. and B.R. Leaton, Amplitude error in the $L$ vector from noisy data, Planet. Space Sci., 17, 483-486, 1969.

Malin, S.R.C., A. Cecere, and A. Palumbo, The sunspot cycle influence on lunar and solar daily geomagnetic variations, Geophys. J. R. Astr. Soc., 41, 115-126, 1975.

Matsushita, S., Solar quiet and lunar daily variation fields, Chap. III-1, in Physics of Geomagnetic Phenomena, edited by S. Matsushita and W.H. Campbel1, pp. 301-424, Academic Press, New York, 1967.

Matsushita, S. and W.H. CAmpbell, Lunar semidiurnal variations of the geomagnetic field determined from 2.5-min data scalings, J. Atmos. Terr. Phys., 34, 1187-1200, 1972. 
Matsushita, S. and H. Maeda, On the geomagnetic lunar daily variation field, J. Geophys. Res., 70, 2559-2578, 1965.

McIntosh, C.H., On the annual variation of magnetic disturbance, Phil. Trans. Roy. Soc., A251, 525-552, 1959.

Onwumechilli, C.A. and N.S. Alexander, Variations in the geomagnetic field at Ibadan, Nigeria-II. Lunar and luni-solar variations in $H$ and $Z, J$. Atmos. Terr. Phys., 16, 115$123,1959$.

Price, A.T., Electromagnetic induction within the earth, Chapter II-3, in Physics of Geomagnetic Phenomena, edited by S. Matsushita and W.H. Campbell, pp. 234-298, Academic Press, New York, 1967.

Priester, W. and D. CAtTANi, On the semi-annual variation of geomagnetic activity and its relation to the solar corpuscular radiation, J. Atmos. Sci., 19, 121, 1962.

RAO, D.R.K., Lunar and luni-solar variations of the geomagnetic field in the Indian region, Pure Appl. Geophys., 95, 131-140, 1972.

RAstogi, R.G., Luni-solar tidal oscillationss in horizontal magnetic intensity $H$ and in foF 2 at Huancayo during low solar activity period, J. Atmos. Terr. Phys., 30, 497-512, 1968 a.

Rastogi, R.G., Lunar tidal oscillations in $H$ at Huancayo during IGY/IGC, Ann. Geophys., 24, 779-788, 1968 b.

Rastogi, R.G. and N.B. Trivedi, Luni-solar tides $H$ at stations within the equatorial electrojet, Planet. Space Sci., 18, 367-377, 1970.

Risbeth, H. and O.K. GARRIOTt, Introduction to Ionospheric Physics, pp. 179-181, pp. 252-270, Academic Press, New York, 1969.

Roosen, J., The seasonal variation of geomagnetic disturbance amplitudes, Bull. Astr. Insts. Neth., 18, 295-305, 1966.

Russell, C.T. and R.L. MCPherron, Semiannual variation of geomagnetic activity, $J$. Geophys. Res., 78, 92-108, 1973.

Schubert, G. and K. Schwartz, Electromagnetic induction in spherical cap current layers under lunar and terrestrial condition, Phys. Earth Planet. Inter., 10, 55-69, 1975.

SHAPIRO, R., Semi-annual variation of geomagnetic disturbance and its modulation of shortest period variations, J. Geophys. Res., 74, 2356-2357, 1969.

SHIRAKI, M., Effect of the ocean dynamo on the lunar daily geomagnetic variation at Kakioka, Memambetsu, and Kanoya, Japan, 1958-1973, Mem. Kakioka Mag. Obs., 17, 51-58, 1978 a.

Shiraki, M., Lunar and solar daily variations in earth current at Kakioka, Japan, Mem. Kakioka Mag. Obs., 17, 78-85, 1978 b.

Siebert, M., Atmospheric tides, Advan. Geophys., 7, 105-187, Academic Press, New York, 1961,

Sugiura, M. and G. Fanselau, Lunar phase numbers $\nu$ and $\nu^{\prime}$ for years 1850 to 2050, U.S. NASA Goddard Space Flight Center, Rept. X-612-66-401, 206 pp., June 1966.

TAKeuchi, H. and M. SAIto, Electromagnetic induction within the earth, J. Geophys. Res., 68, 6287-6291, 1963.

TARPley, J.D., The ionospheric wind dynamo, 1, Lunar tide, Planet. Space Sci., 18, 10751090, 1970.

TARPley, J.D., The $O_{1}$ component of the geomagnetic lunar daily variation, J. Geomag. Geoelectr., 23, 169-179, 1971.

TARPley, J.D. and B.B. Balsley, Lunar variations with the Purvian electrojet, J. Geophys. Res., 77, 1951-1960, 1972.

WARD, F.W., Jr., The variance (power) spectra of $C i, K p$, and $A p, J$. Geophys. Res., 65, 23592373, 1960.

WERTZ, R. and W.H. CAMPBELL, Integrated power spectra of geomagnetic field variations with periods of 0.3-300 s, J. Geophys. Res., 81, 5131-5140, 1976. 
WILcox, J.M., The interplanetary magnetic field, solar origin and terrestrial effects, Space Sci. Rev., 8, 258-328, 1968.

Wilkes, M.V., Oscillations of the Earth's Atmosphere, Cambridge University Press, Cambridge, 1949.

Winch, D.E., Geomagnetic lunar partial tides, J. Geomag. Geoelectr., 22, 291-318, 1970.

YonezAWA, T., On the seasonal, non-seasonal, and semi-annual variations in the peak electron desity of the F2 layer at noon in the equatorial zone, in Report on Euatorial Aeronomy, edited by F. de Mendonca, pp. 123-128, CNAE, San Jose dos Campos, Brasil, 1965. 